\title{
Demography and market impacts on dental practices' development in Bulgaria during the period of transition 1990-2010
}

\author{
Lydia Katrova, Krassimir Tzokov
}

Department of Public Health, Faculty of Dental Medicine, Medical University of Sofia, Sofia, Bulgaria

\author{
Corresponding author: \\ Lydia Katrova \\ Department of Public Health \\ Faculty of Dental Medicine \\ Medical University of Sofia \\ Georgi Sofiiski 1, Sofia 1431 \\ Bulgaria \\ lydia_katrova@yahoo.com \\ Tel.: + 0035929541230 \\ Fax.: + 0035929521506
}

Received: 2 March 2013

Accepted: 11 May 2013

Copyright (C) 2013 by

Academy of Sciences and Arts

of Bosnia and Herzegovina.

E-mail for permission to publish:

amabih@anubih.ba
Objective. The purpose of this study was to present the impact of demography and market dynamics on the organizational and technological development of dental practices in Bulgaria during the period of socio-economic transition from 1990 to 2010. Material and methods. Relevant data were gathered from the official registers of the Bulgarian Dental Association, National Health Insurance Fund, National Health Information Institute and research studies, published during the period 1990-2010. They were analysed and are discussed in this paper. Results. During the period there was a decrease in population of Bulgaria, from $8,149,468$ in 2000 to $7,563,000$ in 2010 and a movement from rural areas to cities. There was an aging population with an increase in oral health care needs at a time of decrease in the size of the national labour force and economic growth. Paradoxically, over the last 20 years, the number of dentists in Bulgaria increased by more than 50\% from 1997 to 2008. The average age of dentists changed from 39.7 years in 1997 to 41.7 years in 2008 . The number of group dental practices increased and the number of individual practices and group practices for specialized dental care and dental centres decreased. The utilization of dental services is currently "about half" that of the mean for all European Union Member States, which is over $80 \%$ per year. Conclusions. The growing number of elderly people who have retained their teeth suggests an increase in treatment needs. However, the decline in their purchasing power limits the demand for oral health care services. In order to meet this and other challenges Bulgarian dentists have started changing their traditional solo-practice to group-practice.

Key words: Dental demography, Dental service, Utilization of dental services.

\section{Introduction}

During the last two decades, dentistry in Bulgaria has faced radical transformation (1). Oral health care evolved from $100 \%$ public funding to almost $100 \%$ private funding. In the early 1990's dentists lost state control and gained the status of liberal practitioners. As a result, access to oral health care for the population as a whole was affected and the utilization of health services declined. New opportunities in organizing practices but challenges from the new social 
and economic environment and the demographic dynamics in the country arose (2).

Demographic data for Bulgaria for this period showed a steady trend of a decrease in the population, an aging population, and an uneven population distribution, with movement from rural areas to cities all over the country. In contrast to the decrease in the number of inhabitants, the number of dentists increased rapidly (3). On one hand, the oral health care market was stimulated, on the other hand, the demographic and economic changes depressed dentists' incomes and their potential to invest in new technology and innovative management (4).

This paper tries to open a discussion on a range of market and professional issues and to define long-term trends in oral health care in Bulgaria which have resulted from the radical social transformations, experienced by the population and the dentists.

The aim of this paper was to present the impact of the demographic changes and the commercialization of dental services on the organizational and technological development of dental practices during the period of socio-economic transition in Bulgaria. In particular, the following areas were investigated: 1. Population demography, 2. Dental demography, 3. Dental practices' development, and 4. Utilization of the oral health care services.

\section{Material and methods}

The study was based on an analysis of secondary data, which were accessed from the official registers of the $\mathrm{NCHI}^{1}$ the $\mathrm{NSI}^{2}$, Bg. $\mathrm{D} \mathrm{A}^{3}$ and research studies, published during the last 20 years.

The analysis of the literature comprised two periods: $(1990-2000)^{4}$ and $(2000-2010)^{5}$

\footnotetext{
${ }^{1}$ National Center for Health Information

${ }^{2}$ National Statistical Institute

${ }^{3}$ Bulgarian Dental Association

${ }^{4}$ The period between 1990 and 2000 is marked by the change of legislation relative to private practice protection (liberalization and privatization).

${ }^{5}$ The second period is characterized by the introduction of the third party payment (regulation).
}

and covered issues relevant to: health reforms (5-7), the professional status of dentists (8, $9)$, trends in dental demography $(10,11)$, the number of dentists and their mobility (12), other dental personnel (13), oral health care service (14), oral treatments' needs (15), utilization of oral health care services (16).

\section{Results}

\section{Population demography}

Based on the official sources, the population of Bulgaria decreased by $8.2 \%$ during the period 2000-2010 (from 8,149,468 in 2000 to $7,563,000$ in 2010) (17).

The age and sex distribution of the population showed a slow but stable trend towards a decrease in the number of younger people and a considerable increase in the proportion of over 65 years olds, usually in rural areas. The number of women remained constant. In the younger age groups there was a slight increase in the male population from $49.5 \%$ to $50.1 \%$. The larger proportion of elderly women is generally due to the higher life expectation of the female population in Bulgaria (Figure 1).

The population is unevenly distributed over the country, in a small number of major cities (18) such as the capital city of Sofia and some large cities of the Black Sea area (Varna and Bourgas). The population there was either relatively constant or growing. Over the years, the size of the urban population increased at the expense of the rural areas (Figure 2).

The aging of the population occurred at a time of decreasing numbers in the labour force. The percentage of the working population was significantly higher in cities, while the villages are more or less depopulated of people of working age. The number of the working population gradually decreased from 2000 to 2005, then slowly increased and has remained stable in recent years (about $65.8 \%$ by the end of the year 2010). This par- 


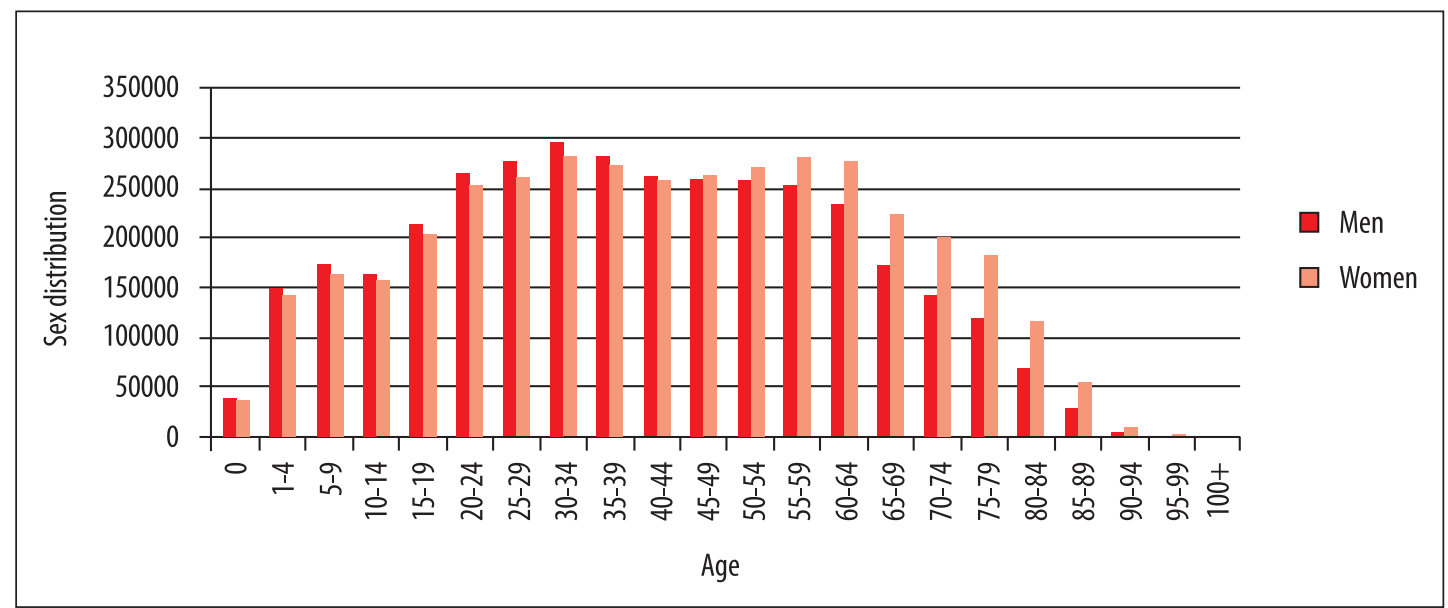

Figure 1 Population of Bulgaria by age and sex distribution (13).

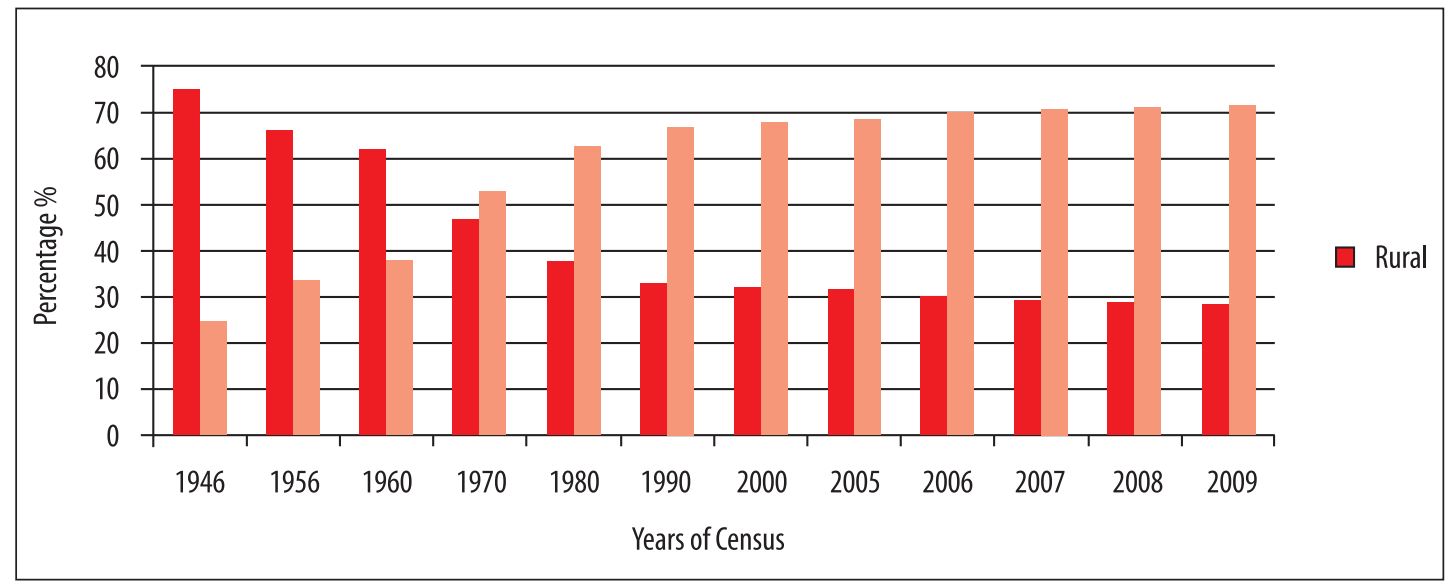

Figure 2 Dynamics of the urban population rate in Bulgaria $(11,17)$.

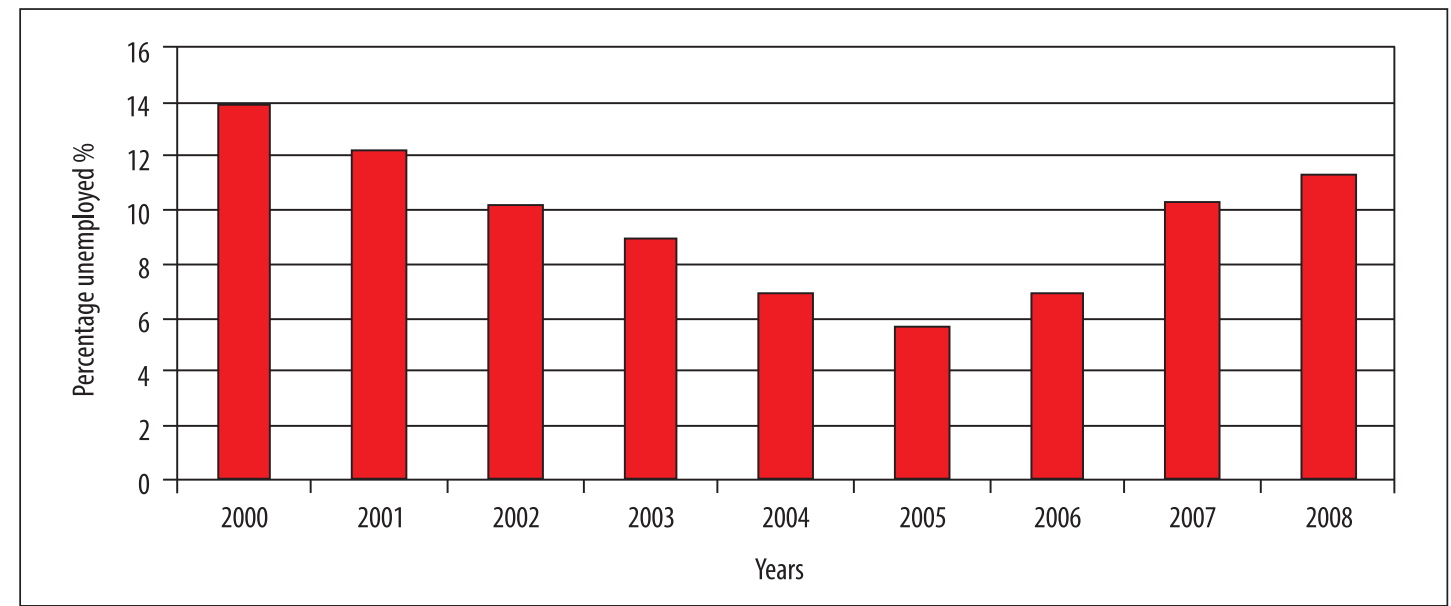

Figure 3 Unemployment rates of population aged between 15 and 64 (19). 
adox is due to an increase in the retirement age from 55.0 years for women and 60.0 for men before 1990, to 62.5 for women and 65.0 for men in 2010. Underemployment and unemployment particularly affect young and poorly educated people (19). The number of long-term unemployed (two or more years) is increasing gradually (Figure 3) (19).

\section{Dental Demography}

The number of dentists in Bulgaria increased considerably during the studied period. After a sharp increase from 1980 to 2000 (from 4,839 to 6,778 ) the speed of increase slowed down in the period 2001-2010. The number of dentists started decreasing in 2011, due to the movement of dentists abroad.

By 2010 there were 8,400 registered dentists in Bulgaria (Figure 4), of whom about $66 \%$ were women, while in 1990 female dentists represented $75 \%$ of the total number of active dentists. A process of defeminization of the dental profession has been observed $(20,21)$.

Two opposing trends could be seen when observing the average age and male: female ratio for the country as a whole and for the capital city of Sofia (22).

Before the changes, the only opportunity for career development resulted from ob- taining a position in the boards of district dental departments or regional dental clinics. Usually these positions were occupied by male dentists (20). Now the only regulator of the number of dentists is the market and no significant difference was found between male and female dentists in their preferences to practice in the capital city or in the countryside (Figure 5a).

The average age of dentists in the country increased from 39.7 years in 1997 to 41.7 years in 2008 , while the average age of dentists in Sofia declined from 40.7 years in 1997 to 39.0 years in 2008 . Sofia is the preferred place of work for newly graduate dentists (Figure 5b).

The distribution of dentists over the country was uneven. The areas of considerable concentration of population were and still are attractive to dentists. The number of dentists in urban centres grew as follows: in Sofia-city (from 1,017 in 2000 to 1,479 in 2009) in Varna (from 381 dentists in 2000 to 426 dentists in 2009), in Plovdiv (from 785 dentists in 2000 to 936 dentists in 2009), in Pernik (from 112 dentists in 2000 to 136 dentists in 2009). The concentration of dentists in particular parts of the country caused a considerable decrease in the dentists/patients ratio, (Figure 6) (23).

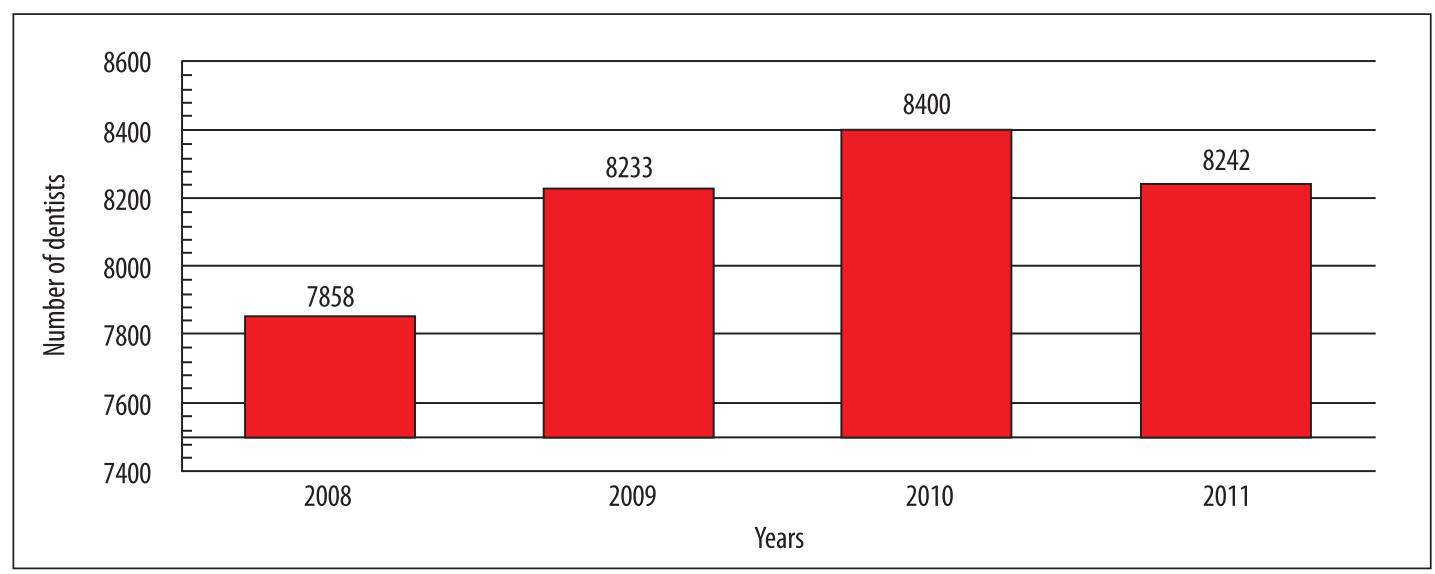

Figure 4 Number of dentists according Bulgarian Dental Association Registers (10). 


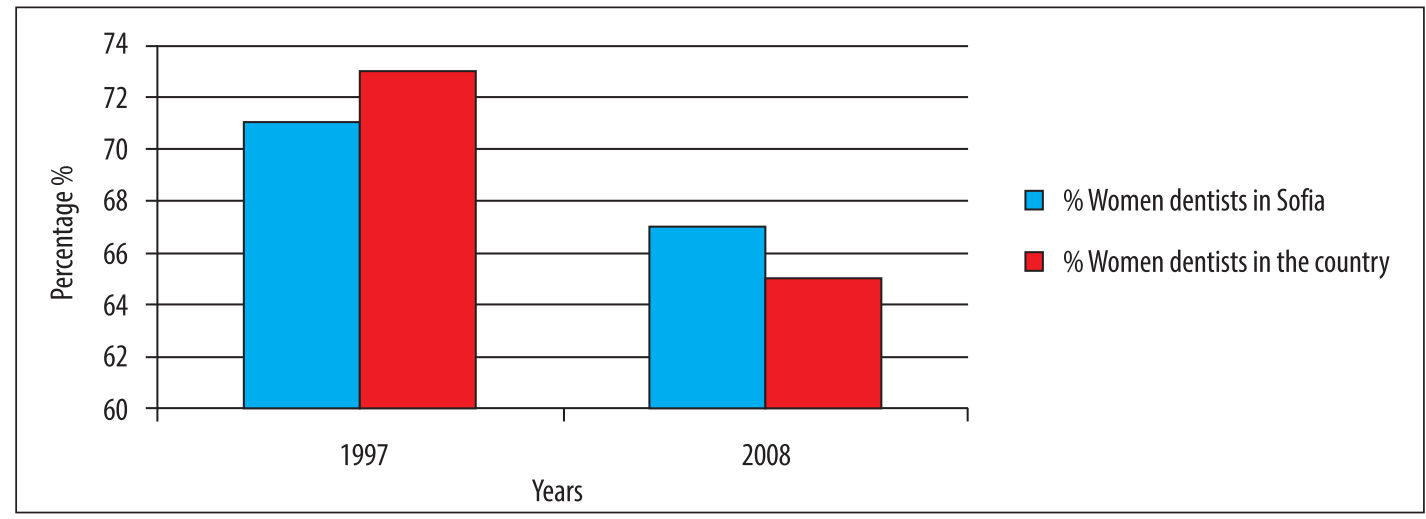

Figure 5a Trends of distribution of women dentists in Sofia and the country.

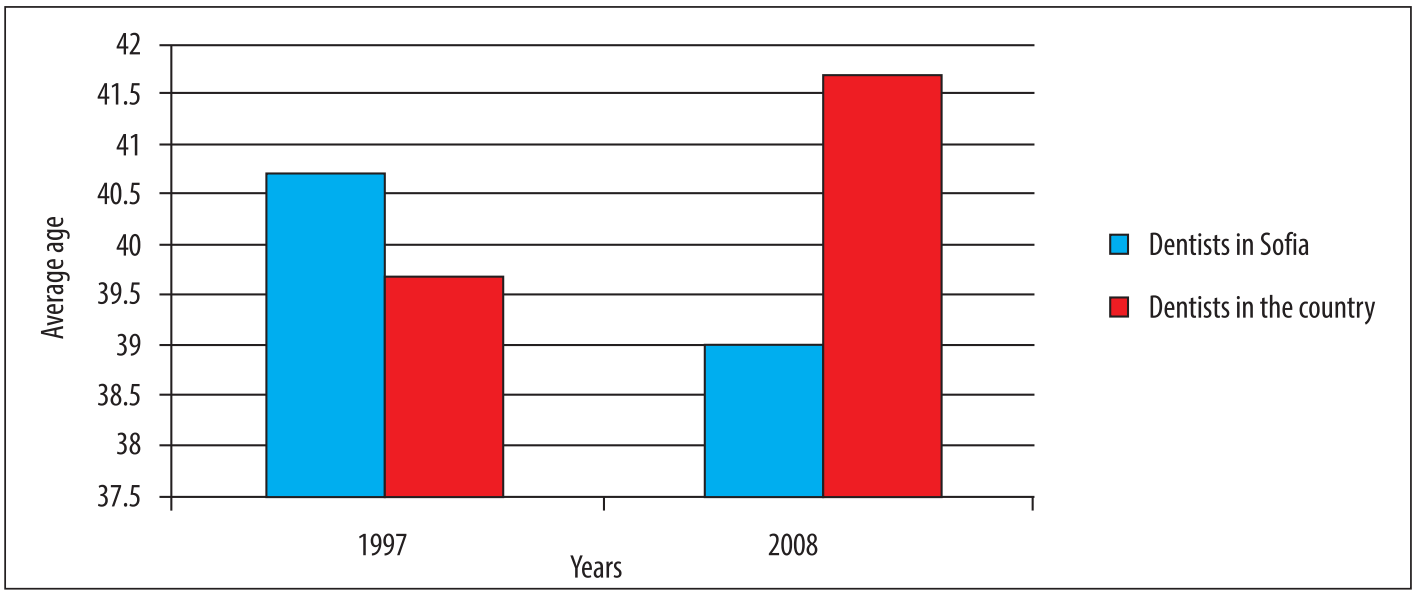

Figure $5 \mathrm{~b}$ Trends of average age of dentists' dynamics in Sofia and the country.

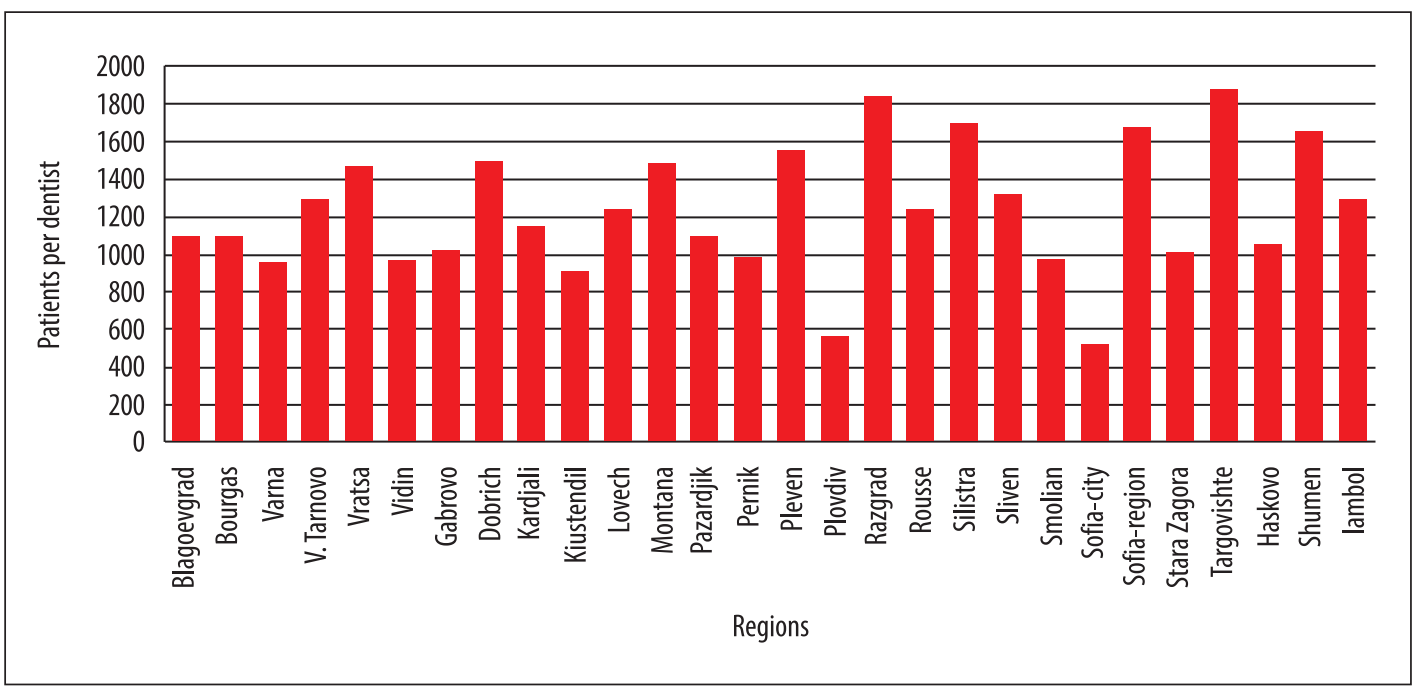

Figure 6 Number of patients per dentist in different regions of the country (13). 


\section{Dental practices' development}

The change in the structure of dental practices was assessed by studying the following: status of ownership and type of practice, professional development, auxiliary staff development, improvement of equipment.

According to data for the period 1991 2001 the status of dentists was irreversibly transformed from employees in the health care system to freelance practitioners. In the next decade (2000-2010) private practitioners started contracting with the national Health Insurance Fund (24).

The Dental Health Service consists of individual and group practices for general and specialized dentistry and dental and medicodental centres. A review of official data on dental practices showed that initially (20002007) the number of individual general dental practices increased, followed by a reduction in the number between 2007 and 2009. There was growth in the number of general dentistry group practices (2000-2009). The number of individual and group practices for specialized dental care was reduced during the same period. The number of dental centres declined, while the number of medico- dental centres remained relatively constant. The reduction in the number of dental centres (from 82 in 2000 to 49 in 2009) was in parallel with no reduction in the number of beds in medico-dental centres (11).

The percentage of general practitioners increased at the expense of the number of specialists. The number of specialists and dentists specializing declined. For the 20 year period only 371 dentists achieved the status of specialist. At the same time, three times as many specialists retired (13). Also, the system for continuous postgraduate education was under the guidance of the $\mathrm{BgDA}$ and private developed educational centres (22).

Only a small percentage of dentists worked with support (auxiliary) staff. The data showed that after an increase in the proportion of dental practices working with auxiliary staff during the period 1996-2000, a period of stagnation followed (2000-2005) with auxiliary staff present in $40 \%$ of practices, followed by a sharp reduction in auxiliary staff utilization for the period 2005-2009 (Figure $7)(13,22)$. The training of nurses is developing accordingly to the assistance utilization.

There was a gradual renewal of dental equipment at the expense of imported

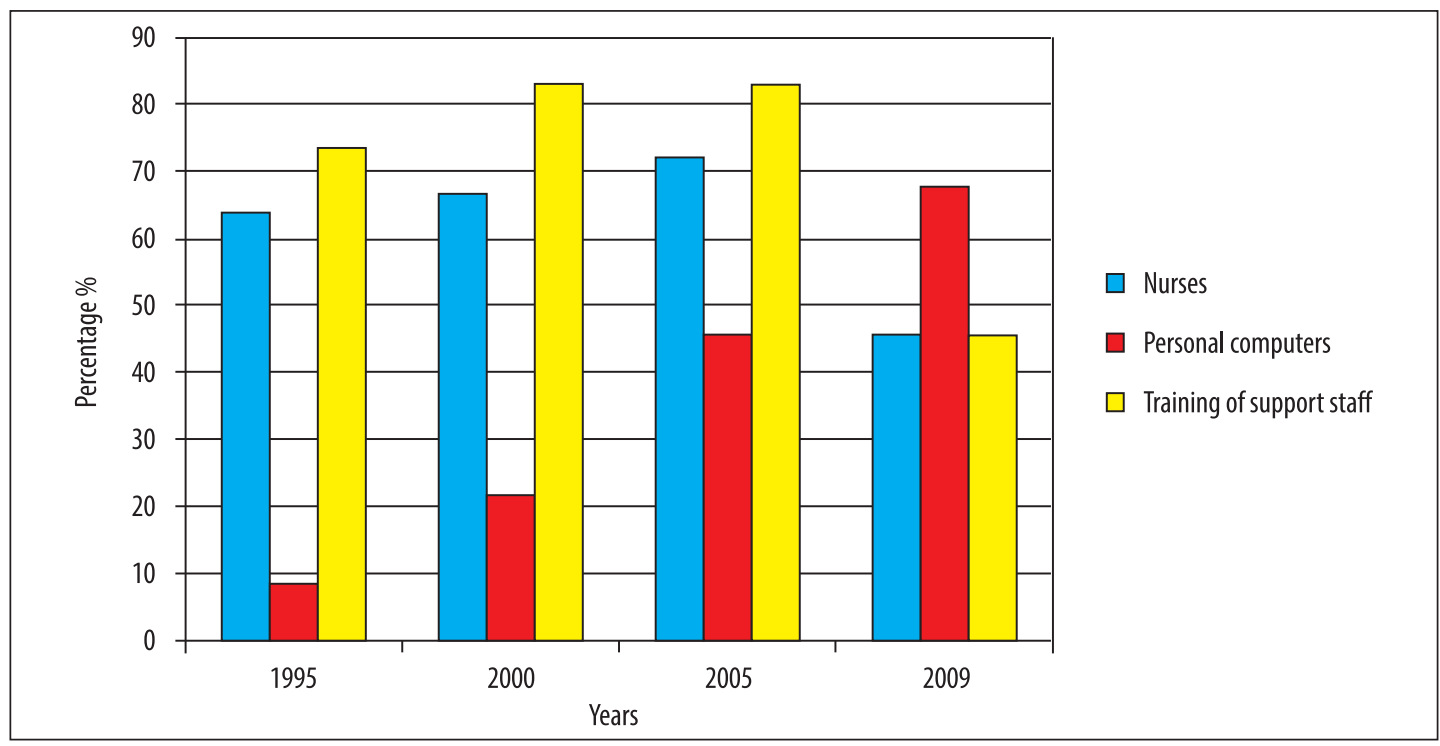

Figure 7 Dental auxiliary staff utilization in dental practices (13). 


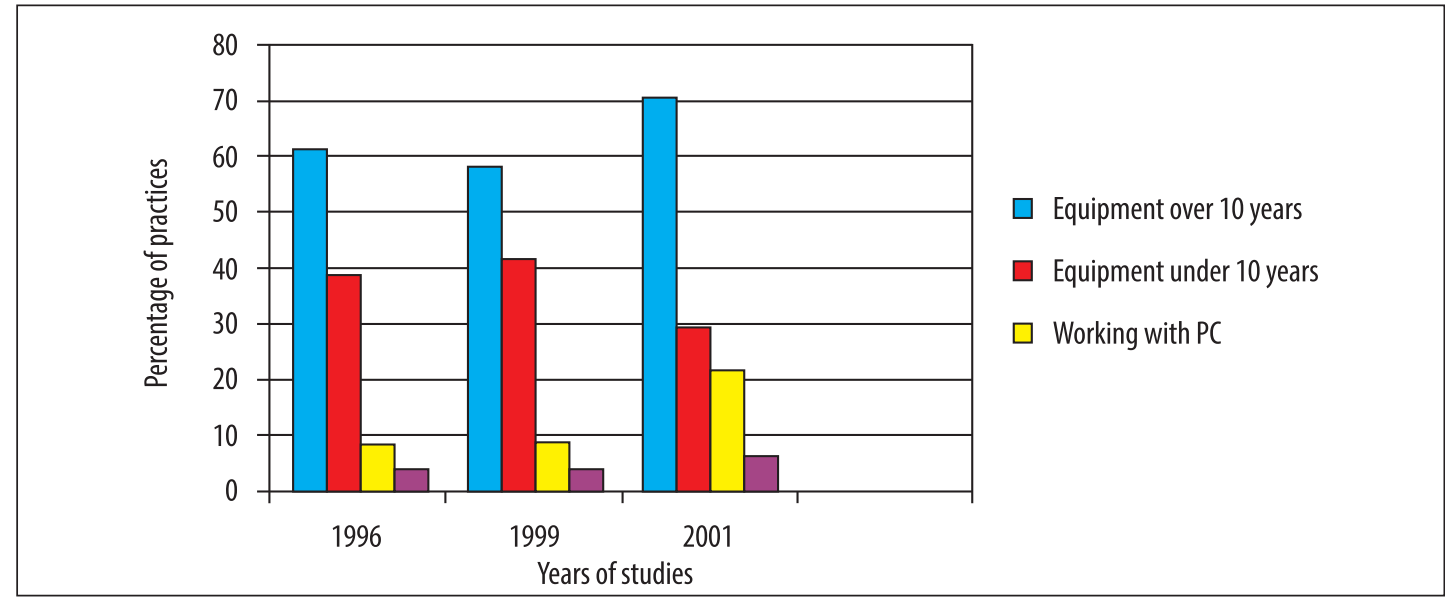

Figure 8 Technological development of dental practices (11).

equipment (from $16.6 \%$ for 1996 , to $17.7 \%$ for 1999 and $24.0 \%$ for 2001). At the same time the tendency of using dental equipment over 10 years old grew (1996 - 61.2\%, 1999 - 58.2\%, 2001 - 70.6\%). Slowly but steadily the percentage of practices providing dental implants grew (1996 - 4.1\%, 1999 - 4.2\%, $2001-6.4 \%)$. The greatest increase was in the number of practices using personal computers (Figure 8) (11)

\section{Utilization of oral health care services}

The percentage of the population aged less than 65 years decreased while the number of dentists markedly increased. The regions of Sofia-city, Plovdiv, Varna, have a constant number of dentists and an unfavourable dentist/patient ratio. The population: dentist ratio permanently decreased (Figure 9).

Utilization of dental services is about 50\% of the mean for the North Western European Union (EU). According to BgDA only $45 \%$ of

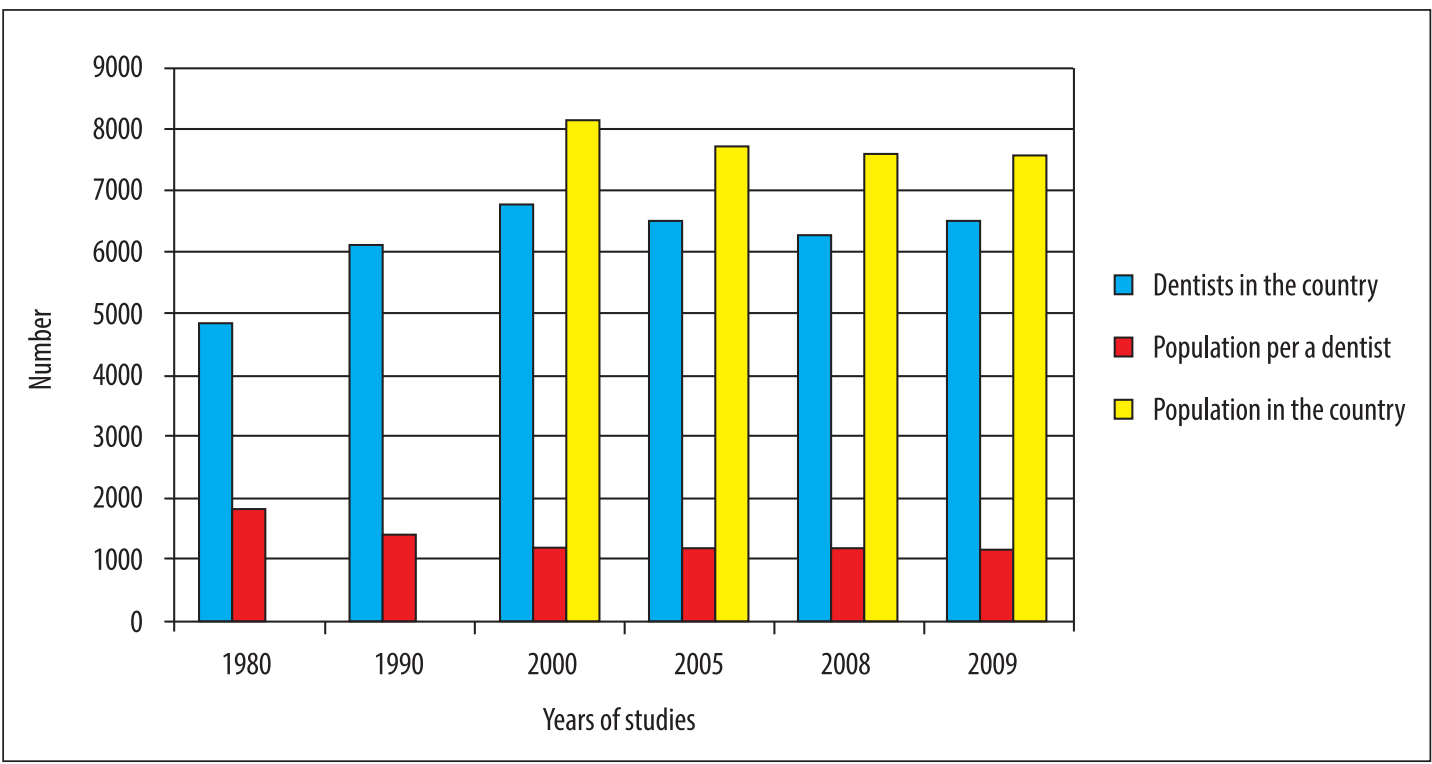

Figure 9 Impact of the demographic changes of the population on patient to dentist ratio for the period (19802009), (11, 27). 
patients had visited a dentist during the previous year, while in some EU Member States the percentage varied from $83 \%$ to $71 \%$ (25).

\section{Discussion}

During the 1991-2001 period the Health Care System in Bulgaria changed from a monopolistic state-organized and stateregulated model to a pluralistic decentralized model, based on the coexistence of market and community-oriented programs, financed by comprehensive national insurance plans. The health reforms aimed at sustainable changes in regulations, financing and resource allocation, similar to the processes in the national economy, which passed through the stages of liberalization, privatization, and stabilization. The perception of the health system as a public resources consumer had to give way to the perception of an ongoing sector of the national and global economies (23). This general frame of reforms was just one factor in the real professional and technological development in dentistry. The lack of public resources and interest in dental health issues of the Government resulted in limitation of access to dental care and a potential decrease in the level of utilization of dental services. The unemployment rate for Bulgaria is relevant to the population's purchasing power, and in particular, its ability to pay for oral health care services and the impact on the rate of utilization of dental services $(19,25)$.

The reduction in the size of the population and its uneven distribution over the country was due to social factors rather than demographic conditions. The most attractive areas for the population are those with lower unemployment rates and better conditions for living, such as: Sofia city, Varna, Bourgas, Plovdiv, as well as destinations abroad. Internal and external migration contributed to significant depopulation of other regions, such as Vidin and Targovishte.
In more densely populated regions, characterized by a relatively highly developed economy, the number of oral health care practices is higher and more dentists are registered, while in less developed regions the number of practices and practitioners is lower (27). Overall, the number of dentists is increasing, but the demand for oral health care is not increasing automatically due to financial restraints on consumers. As a result, the migration of the population is followed by migration of dentists in the same direction - from small villages to large agglomerations and / or outside the country. De-feminization of the profession is a lasting trend (22).

Dental practices are characterized by a clear trend towards technological innovation, while retaining the gap between the technology and team development. A surplus of technological innovation, training and equipment, without taking account of the available specialists and their implementation, and ignoring the problems of dental teams, will create new challenges for dentists to develop their practices (13).

\section{Conclusions}

The increase in the proportion of Bulgarians over the age of 65 years implies an increase in treatment needs. The decline of purchasing power of the aging population limits the demand for oral health care services. In order to meet the market expectations for technological development, dentists have changed their traditional solo-practice orientation towards group-practice organization. Further research should be focused on oral health care service utilization and the dental practices' preparedness to respond to the real demand for oral health care.

Authors' contributions: Conception and design: LK, KT; Acquisition of data: KT, LK. Analysis and interpretation of data: LK, KT; Drafting the article: KT and LK; Revising it critically for important intellectual content: LK, KT. 
Conflict of interest: The authors declare that they have no conflict of interest.

\section{References}

1. Widström E, Eaton KA, Borutta A, Dybizbánska E, Broukal Z. Oral Healthcare in Transition in Eastern Europe. Brit Dent J. 2001;190(11):580-4.

2. Koulaksazov S, Todorova S, Tragakes E, Hristova S. In: Tragakes E, editor. Health Care Systems in Transition: Bulgaria. Copenhagen: European Observatory on Health Care Systems; 2003.

3. Katrova L. Systems for the provision of oral health care in the black sea countries. Part 2: Bulgaria. Oral Health and Dental Management in the Black sea countries. 2009;8(2):3-7.

4. Katrova LG. Dental public health, dental profession, dental practice. 1st ed. Sofia: "WINI 1893"; 2011.

5. Katrova L, Katrova T. Politique Sociale en Europe de l'Est: le cas de la sante. In: Krasteva A, Todorov A, editors. La mondialization et les nouvelles limites du politique. Sofia: EOH-2000; 2004. p. 209-19.

6. Katrova L. Health reforms during the transition period and Bulgarian dental policy reform of 1991-2001 and their impact on dental education. SocMed (Sofia). 2009;17(1/2):20-3.

7. Katrova L, Bojinov P, Mihailova I. Oral health care reforms in Bulgaria during the period of transition. Oral health and Dental Management in the Black Sea Countries. 2007;6(4):3-8.

8. Katrova L, Tzokov K, Katrova T. The health reforms and the change of the socio-professional status of dentists in Bulgaria. Problems of Dentistry. 2003;29(5):46-50.

9. Katrova L. Ethical, legal, and professional foundations of the autonomous regulation of the dental profession, the case of Bulgaria. JofIMAB. 2010;16(4):70-6.

10. Bulgarian Dental Association. Registers 2011 [cited 2011 Sep 18]. Available from: http://www.bzs. bg/site/index.php.

11. Tzokov K, Katrova L. Demographic process and structure of dental practices as prerequisites for market development of the dental services in Bulgaria. Problems of Dental Medicine. 2011;37(2):61-5.

12. Katrova L. Generational mobility within dental profession, succession in career choice and perspectives for professional realization in Bulgaria. SocMed (Sofia). 2009;17(3):29-32.

13. Katrova L, Tzokov K. Current status of the dental practice in Bulgaria. Meta-analysis. J of IMAB. [DOI:105272/jimab.2012/182.181]. 2012;18(2):181-7.
14. WHO. The World Health Report 2000: Health Systems: Improving Performance. Geneva: WHO; 2000.

15. Katrova L, Papanchev G, Borissova T, Benkin N. Meeting the needs for caries and caries complication treatment by dentists working under contract with the national health insurance fund (under progress investigation). Problems of Dentistry. 2004;30(6):63-8.

16. Katrova L, Grashkina M. Utilization of the oral health service during the period of transition. J of IMAB. 2000;6(2):246-50.

17. National Statistical Institute. Census 2011 [cited 2012 Feb 28]. Available from: http://www.nsi.bg/ census2011/index.php.

18. World Bank. World Development Report 1998 1999: Knowledge for Development. New York: Oxford University Press; 1998.

19. National Statistical Institute. Labour Market [cited 2012 Feb 20]. Available from: http://www.nsi.bg/ otrasal.php? otr $=26 \& a 1=735 \& a 2=741 \& a 3=745 \#$ cont.

20. Katrova L. Gender impact on the socioprofessional identification of dentists in Bulgaria. J Dent Educ. 2004;68 (Suppl 7):S19-22.

21. Katrova L, Surcheva Zh. Career path dynamics of female dentists: actual status and trends. Med Pregled. 2004;40(4):84-9.

22. Katrova L, Tzokov K. Women dental practitioners - the organization of their dental practice particularity. SocMed (Sofia). 2012;20(2/3):59-61.

23. World Bank. Assessing Globalization: World Bank Briefing Papers. Washington, DC: PREM Economic Policy Group and Development Economics Group; 2000.

24. WHO. In: Anna Ritsatakis, Ruth Barnes, Evert Dekker, Patsy Harrington, Simo Kokko, Peter Makara. Exploring Health Policy Development in Europe. Copenhagen: World Health Organization: Regional Office for Europe; 2000.

25. Special Eurobarometer 330. Report Oral Health. 2010. Conducted by TNS Opinion \& Social at the request of Directorate General Health and Consumers Survey co-ordinated by Directorate General Communication; 2010. p. 112 [cited 2012 Dec 16]. Available from: http://ec.europa.eu/public_ opinion/archives/ebs/ebs_330_en.pdf.

26. Hobdell M, Sinkford J, Alexander C, Alexander D, Corbet E, Douglas C et al. 5.2. Ethics, equity and global responsibilities in oral health and disease. Eur J Dent Educ. 2002;6(Suppl 3):S167-78.

27. National Centre for Health Information. Brief Statistical Book: 2000, 2001, 2002, 2003, 2004, 2005, 2006, 2007, 2008, 2009, 2010 [cited 2012 Dec 26]. Available from: http://www.nchi.government.bg. 